\title{
A Hybrid Stochastic-Interval Analytic Hierarchy Process Approach for Prioritizing the Strategies of Reusing Treated Wastewater
}

\author{
Liang Jing, ${ }^{1}$ Bing Chen, ${ }^{1,2}$ Baiyu Zhang, ${ }^{1}$ and $\mathrm{Pu} \mathrm{Li}^{1}$ \\ ${ }^{1}$ Northern Region Persistent Organic Pollution Control (NRPOP) Laboratory, Faculty of Engineering and Applied Science, \\ Memorial University of Newfoundland, St. John's, NL, Canada A1B 3X5 \\ ${ }^{2}$ Key Laboratory of Regional Energy and Environmental Systems Optimization, Ministry of Education, \\ Resources and Environmental Research Academy, North China Electric Power University, Beijing 102206, China
}

Correspondence should be addressed to Bing Chen; bchen@mun.ca

Received 26 February 2013; Accepted 31 March 2013

Academic Editor: Guohe Huang

Copyright (C) 2013 Liang Jing et al. This is an open access article distributed under the Creative Commons Attribution License, which permits unrestricted use, distribution, and reproduction in any medium, provided the original work is properly cited.

\begin{abstract}
This paper proposes a hybrid stochastic-interval analytic hierarchy process (SIAHP) approach to address uncertainty in group decision making by integrating interval judgment, probabilistic distribution, lexicographic goal programming, and Monte Carlo simulation. A case study related to wastewater treatment plant (WWTP) effluent reuse was conducted to demonstrate the feasibility of the proposed approach. Four candidate alternatives including city moat landscaping, municipal reuse, industrial reuse, and agricultural irrigation were evaluated by five experts according to technical, economic, and environmental criteria. The results suggest that industrial reuse $(0.18-0.3)$ is more preferred over municipal reuse $(0.16-0.25)$ or agricultural irrigation $(0.17-0.26)$ in most replications. The final score of city moat landscaping ranges from 0.11 to 0.31 which indicates a great divergence of expert opinions. It can be concluded that choosing industrial reuse seems to give the best overall account of technical, economic, and environmental concerns. The proposed SIAHP approach can aid group decision making by accommodating linguistic information and dealing with insufficient information or biased opinions.
\end{abstract}

\section{Introduction}

As a major factor influencing social and economic development, the global water shortage has been exacerbated due to population growth, urbanization, climate change, and industrialization [1-4]. The reuse of treated wastewater from wastewater treatment plants (WWTPs) has been gaining significant attention as a potential solution to cope up with the increasing water stress. Possible beneficial applications include, but are not limited to, toilet flushing, irrigation, groundwater recharge, fire protection, cooling water, landscaping, boiler feed water, and some working procedures of stocking, pulping, and paper making [5-7]. It is of importance that conventional WWTPs are commonly designed to remove suspended solids and bulk organics rather than pathogenic microorganisms. Therefore, treated wastewater may still contain significant levels of fecal coliforms and many other pollutants (e.g., heavy metals) that need to be removed prior to reuse. Friedler et al. highlighted that improper planning of wastewater reuse may expose people to hazardous pathogenic microorganisms, posing a serious threat to public health [6]. Kon and Watanabe argued that the promotion of reusing treated wastewater can be compromised by many factors such as the need for posttreatment, the concerns associated with water quality and functionality, and the economic efficiency [8]. Former works have shown that the selection of reuse schemes depends not only on their technical, economic, and environmental feasibility but also mainly on public support, in other words, the decision makers who represent the interests of society.

Decision makers usually use multicriteria decision making (MCDM) methods to aid the decision making process [9-15]. A widely used one is the analytic hierarchy process (AHP), a prominent tool for making decisions in situations 
involving multiple objectives [12]. Many investigations have been undertaken in the past to apply the AHP to problems with high complexity and uncertainty, especially in the environmental sector $[9,16-20]$. Despite its numerous applications, there are critiques in the literature about using inconvenient crisp values and not including uncertainty analysis. Rosenbloom reported that alternatives are not statistically distinguishable if their scores are too close [21]. That is to say, the AHP is not capable of addressing statistical interactions or feedback dependency between different hierarchies of a decision making problem [22, 23]. Another major drawback lies on its inability to translate the imprecision of the decision maker's perceptions [24]. The exact nine-point AHP scale used in pairwise comparisons may fail to capture the imprecision or vagueness in the mind of respondents [25].

In response to these drawbacks, there have been many research attempts on incorporating interval uncertainty into the AHP. It has been well accepted that decision makers are more comfortable and confident to give interval judgments rather than to evaluate pairwise comparisons using single numeric values. Islam developed a lexicographic goal programming (LGP) approach in estimating weight vectors from interval pairwise comparison matrices (IPCMs) [5]. Wang et al. stated that fuzzy inputs can also be addressed by IPCMs using $\alpha$-level sets and the extension principle [26]. Chandran et al. presented a method to estimate the weights of IPCMs based on linear programming [27]. Yu et al. advanced the LGP method by using multiplicative constraints to cope with the inherent deficiencies. On the other hand, to reflect the statistical characteristics of the traditional AHP, pairwise comparison elements were suggested to be viewed as random variables and computed via Monte Carlo simulation [9]. The triangular distribution is the most commonly used distribution for modeling expert judgment in the AHP $[28,29]$. It is advantageous over normal distribution and lognormal distribution due to its bounded nature. However, it may place too much emphasis on the most likely value [22]. It is possible to overcome this disadvantage by using the uniform distribution, which is not much affected by the lack of information. To date, there has been no study specifically investigating how to handle both interval and probabilistic uncertainty in the AHP. Therefore, the objective of this study is to address such issue by integrating interval judgments, probabilistic distribution, the LGP method, and Monte Carlo simulation as a hybrid stochastic-interval analytic hierarchy process (SIAHP) approach. A case study of prioritizing the strategies of reusing treated wastewater from a WWTP in the city of Shuangcheng, China, was carried out to verify the feasibility and efficiency of the proposed approach.

\section{Methodology}

The proposed SIAHP approach uses expert knowledge as interval judgments and aggregates the lower and upper bounds into two independent arrays. For each nondiagonal element in the upper portion of each IPCM, the uniform distribution is assumed on both arrays such that random lower and upper bounds can be generated using Monte Carlo simulation. The lexicographic goal programming (LGP) method is then employed to estimate the priorities of each IPCM. The detailed steps are summarized as follows.

Step 1. Define the problem and structure the hierarchy from the top (i.e., goal) to the bottom (i.e., decision alternatives).

Step 2. Construct IPCMs for alternatives (or criteria) on each hierarchy level in terms of their performance against the ones on the level immediately above. Note that the IPCMs are reciprocal matrices which means judgments are required only for the upper portion:

$$
\left[\begin{array}{ccccc}
1 & a_{12} & a_{13} & \cdots & a_{1 n} \\
\frac{1}{a_{12}} & 1 & a_{23} & \cdots & a_{2 n} \\
\frac{1}{a_{13}} & \frac{1}{a_{23}} & 1 & \cdots & a_{3 n} \\
\vdots & \vdots & \vdots & \cdots & \vdots \\
\frac{1}{a_{1 n}} & \frac{1}{a_{2 n}} & \frac{1}{a_{3 n}} & \cdots & 1
\end{array}\right]
$$

Step 3. Expert opinions are collected as intervals through questionnaires, interviews, surveys, and round-table discussion (2). The upper and lower bounds should not exceed the standard preference scale where 1 represents equal importance and 9 stands for absolute importance

$$
\left[\begin{array}{ccccc}
1 & {\left[l_{12}, u_{12}\right]} & {\left[l_{13}, u_{13}\right]} & \ldots & {\left[l_{1 n}, u_{1 n}\right]} \\
{\left[\frac{1}{u_{12}}, \frac{1}{l_{12}}\right]} & 1 & {\left[l_{23}, u_{23}\right]} & \ldots & {\left[l_{2 n}, u_{2 n}\right]} \\
{\left[\frac{1}{u_{13}}, \frac{1}{l_{13}}\right]} & {\left[\frac{1}{u_{23}}, \frac{1}{l_{23}}\right]} & 1 & \ldots & {\left[l_{3 n}, u_{3 n}\right]} \\
\vdots & \vdots & \ldots & \vdots \\
{\left[\frac{1}{u_{1 n}}, \frac{1}{l_{1 n}}\right]\left[\frac{1}{u_{2 n}}, \frac{1}{l_{2 n}}\right]\left[\frac{1}{u_{3 n}}, \frac{1}{l_{3 n}}\right]} & \ldots & 1
\end{array}\right],
$$

where $l$ and $u$ are the lower and upper bounds of interval judgments, respectively.

Step 4. For each expert-assessed nondiagonal element in the upper portion of each IPCM (e.g., $a_{12}=\left[l_{12}, u_{12}\right]$ ), the lower and upper bounds of different opinions are categorized into two individual arrays, respectively. For both arrays, their maximum and minimum values are determined such that the uniform distribution can be employed in between. Note that the uniform distribution is assumed because the number of participating experts is usually limited. If more experts are involved in the evaluation process, many other distributions 


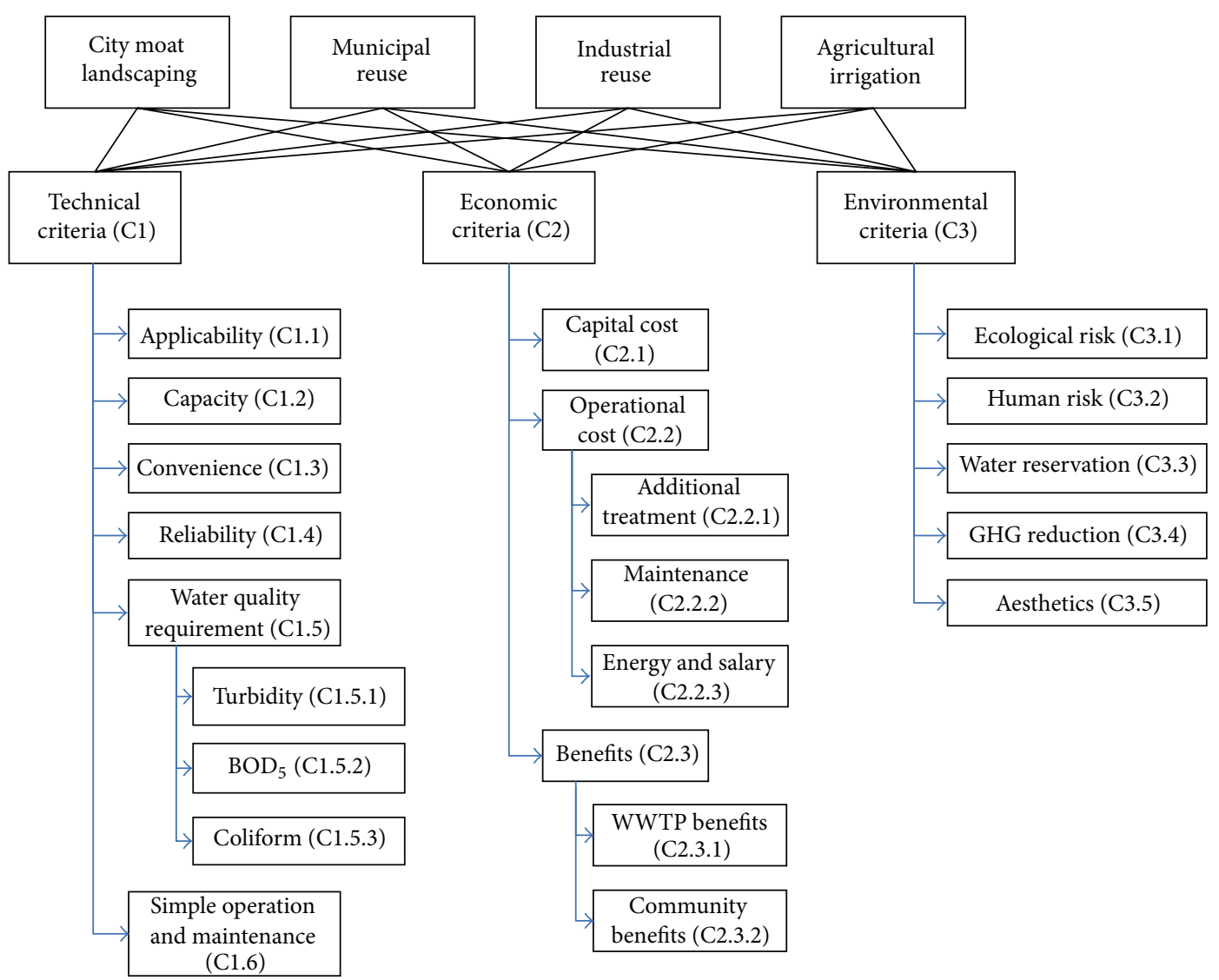

FIGURE 1: Criteria hierarchy for the selection of wastewater reuse alternatives.

TABLE 1: Quantitative database for reclaimed wastewater reuse.

\begin{tabular}{|c|c|c|c|c|c|c|c|}
\hline \multirow{2}{*}{\multicolumn{2}{|c|}{$\begin{array}{cc}\text { Subcriteria } & \text { Description } \\
\text { Reclaimed wastewater reuse }\end{array}$}} & \multirow{2}{*}{ Units } & \multicolumn{4}{|c|}{ Alternatives } & \multirow{2}{*}{ Reference } \\
\hline & & & CML & \multirow{2}{*}{$\frac{\mathrm{MR}}{2}$} & \multirow{2}{*}{$\frac{\mathrm{IR}}{3}$} & \multirow{2}{*}{$\frac{\mathrm{AI}}{2}$} & \\
\hline C1.5.1 & Turbidity & NTU & 3 & & & & {$[30]$} \\
\hline C1.5.2 & $\mathrm{BOD}_{5}$ & $\mathrm{mg} / \mathrm{L}$ & 20 & 10 & 20 & 10 & {$[30]$} \\
\hline C1.5.3 & Coliform & $/ 100 \mathrm{~mL}$ & 23 & 2.2 & 23 & 14 & {$[30]$} \\
\hline $\mathrm{C} 2.1$ & Capital cost & $\$ /$ ton & 110 & 350 & 350 & 110 & {$[31]$} \\
\hline $\mathrm{C} 2.2 .2$ & Maintenance & $\$ /$ ton & 0.03 & 0.09 & 0.09 & 0.03 & {$[31]$} \\
\hline C2.3.1 & WWTP benefits & $\$ /$ ton & 0.05 & 0.2 & 0.16 & 0.03 & {$[30]$} \\
\hline
\end{tabular}

(e.g., normal, beta) that require more precise knowledge can be used.

Step 5. For each aforementioned upper portion element (e.g., $\left.a_{12}=\left[l_{12}, u_{12}\right]\right)$, generate uniformly distributed pseudorandom numbers and map them to the ranges of the two arrays (i.e., the lower and upper bounds) predefined in Step 4. Note that the ranges may intersect and hence the random upper bound must be greater than or equal to the random lower bound. The lower portion of each IPCM can be determined by taking the reciprocal values of the corresponding upper portion. At the end of this step, a series of random IPCMs are obtained such that their non-diagonal elements are random intervals.
Step 6. The lexicographic goal programming (LGP) method is used to estimate the weight vector [23], $W=\left(w_{1}, \ldots, w_{n}\right)$, of each IPCM of rank $n$. The interval judgments contained in the IPCMs can be defined by the following inequality:

$$
l_{i j} w_{j}-p_{i j} \leq w_{i} \leq u_{i j} w_{j}+q_{i j}
$$

where $l_{i j}$ and $u_{i j}$ are the randomly generated lower and upper bounds of each element, respectively, $w_{i}$ and $w_{j}$ are real numbers representing the weights of the $i$ th and $j$ th entries, and deviation variables $p_{i j}$ and $q_{i j}$ are nonnegative real numbers. The weight vector can be derived by minimizing the inconsistency of the upper portion of the interval comparison 
matrix, in other words, a summation of all deviation variables $p_{i j}$ and $q_{i j}$ as stated in the following:

$$
\operatorname{Min} Z=\sum_{i=1}^{n-1} \sum_{j=i+1}^{n}\left(p_{i j}+q_{i j}\right)
$$

subject to

$$
\begin{aligned}
& w_{i}-w_{j} u_{i j}-q_{i j} \leq 0 \\
& -w_{i}+w_{j} l_{i j}-p_{i j} \leq 0 \\
& \sum_{i=1}^{n} w_{i}=1 \\
& w_{i} \geq 0, \quad p_{i j} \geq 0, \quad q_{i j} \geq 0 .
\end{aligned}
$$

Step 7. As with the traditional AHP, the inconsistency of judgements needs to be examined in order to ensure the validity of the random IPCMs. In this approach, the summations of all deviation variables $Z$ are expected to be less than or equal to 0.1 ; otherwise, the IPCM should be declined and regenerated.

Step 8. The final scores of each decision alternative can be calculated by aggregating the weights throughout the hierarchy as follows:

$$
A_{k(\text { Score })}=\sum_{j=1}^{p}\left(b_{k j} \cdot W_{j}\right) \text {, }
$$

where $A_{k \text { (Score) }}$ is the final performance score for the $k$ th alternative, $b_{k j}$ is the merit of the $k$ th alternative with regard to the $j$ th criterion on the preceding level, $p$ is the number of criteria, and $W_{j}$ is the normalized weight of the $j$ th criterion against the goal.

Step 9. Repeat Steps 5 through 8 using Monte Carlo simulation for a number of replications. The overall scores of decision alternatives can be obtained as probability density functions.

\section{Case Study}

3.1. The WWTP of the City of Shuangcheng. The study area (the city of Shuangcheng) is located at the southern end of Heilongjiang province, northeastern China, approximately 45 kilometers southwest from the provincial capital Harbin. As one of the major cities in the province, the city of Shuangcheng has a population of 830 thousand with 640 thousand people dependent on agriculture. An advanced wastewater treatment plant associated with a drainage system was built in 2009 and has been operated since then to treat sewage and wastewater from individual residences, businesses, schools, and so forth. This wastewater treatment plant has a daily treatment capacity of 30,000 tonnes, which is sufficient for population growth and any future expansion demand. However, some important issues with regard to the operation of the treatment plant have been emerging, such as
TABLE 2: Alternatives' normalized scores for quantitative criteria.

\begin{tabular}{lccccc}
\hline Subcriteria & Description & \multicolumn{4}{c}{ Normalized scores of alternatives } \\
Reclaimed wastewater reuse & CML & MR & IR & AI \\
\hline C1.5.1 & Turbidity & 0.300 & 0.200 & 0.300 & 0.200 \\
C1.5.2 & BOD $_{5}$ & 0.333 & 0.167 & 0.333 & 0.167 \\
C1.5.3 & Coliform & 0.370 & 0.035 & 0.370 & 0.225 \\
C2.1 & Capital cost & -0.120 & -0.380 & -0.380 & -0.120 \\
C2.2.2 & Maintenance & -0.125 & -0.375 & -0.375 & -0.125 \\
C2.3.1 & WWTP benefits & 0.114 & 0.455 & 0.364 & 0.068 \\
\hline
\end{tabular}

TABLE 3: Uniform distributions (in MATLAB) of the PCM with regard to human risk.

\begin{tabular}{lccc}
\hline & Min & Max & Uniform distribution \\
\hline$l_{12}$ & $1 / 2$ & 4 & $1 / 2+$ rand $\times(4-1 / 2)$ \\
$l_{13}$ & $1 / 6$ & 1 & $1 / 6+$ rand $\times(1-1 / 6)$ \\
$l_{14}$ & 1 & 1 & $1+\operatorname{rand} \times(1-1)$ \\
$l_{23}$ & $1 / 9$ & $1 / 4$ & $1 / 9+\operatorname{rand} \times(1 / 4-1 / 9)$ \\
$l_{24}$ & $1 / 7$ & 3 & $1 / 7+\operatorname{rand} \times(3-1 / 7)$ \\
$l_{34}$ & 2 & 6 & $2+\operatorname{rand} \times(6-2)$ \\
$u_{12}$ & 3 & 7 & $3+\operatorname{rand} \times(7-3)$ \\
$u_{13}$ & $1 / 3$ & 3 & $1 / 3+\operatorname{rand} \times(3-1 / 3)$ \\
$u_{14}$ & 5 & 7 & $5+\operatorname{rand} \times(7-5)$ \\
$u_{23}$ & $1 / 6$ & 2 & $1 / 6+\operatorname{rand} \times(2-1 / 6)$ \\
$u_{24}$ & 1 & 6 & $1+\operatorname{rand} \times(6-1)$ \\
$u_{34}$ & 4 & 8 & $4+\operatorname{rand} \times(8-4)$ \\
\hline
\end{tabular}

how to optimize the operating parameters to adapt to varying environmental conditions, how to effectively use the treated effluent, sludge, and other byproducts, and particularly how to efficiently operate this plant in a sustainable manner. In this case study, the local government invited experts to evaluate wastewater reuse options in order to explore the possibility of saving natural water resources in the future.

\subsection{Management of the WWTP Effluent}

3.2.1. Goal, Decision Alternatives, and Evaluation Criteria. The goal of this case study was to select the best alternative for WWTP effluent management and to provide the local government with a more systematic overview of sustainable development. Four reclaimed water reuse alternatives including city moat landscaping (CML), municipal reuse (MR), industrial reuse (IR), and agricultural irrigation (AI) were chosen based on the literature review and discussion with experts from local authorities and educational institutions (Figure 1). The city of Shuangcheng is surrounded by a city moat that uses a large amount of water every day to maintain water level and water quality. It is not just a landmark of the city's history but also a tourist attraction. Treated wastewater can be safely discharged into the moat to replenish its water supply and to improve water quality on a daily basis. Treated wastewater can be reused for certain restricted municipal purposes such as firefighting, irrigation of parks and golf courses, street cleaning, groundwater recharging, 


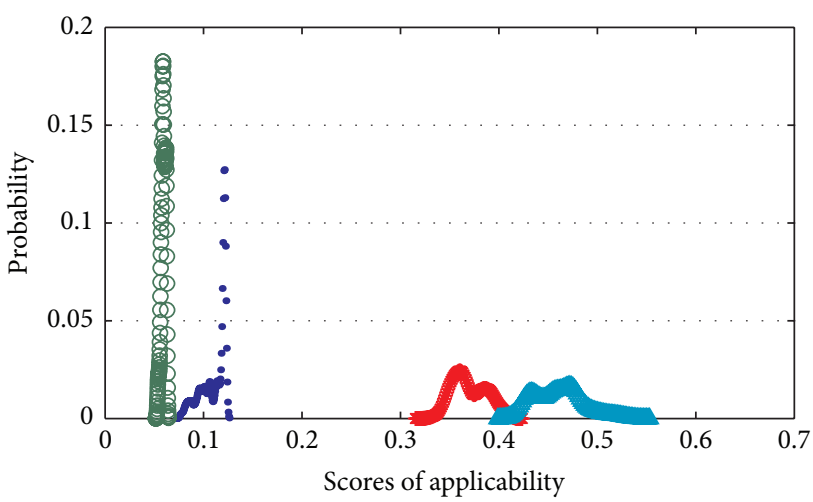

(a)

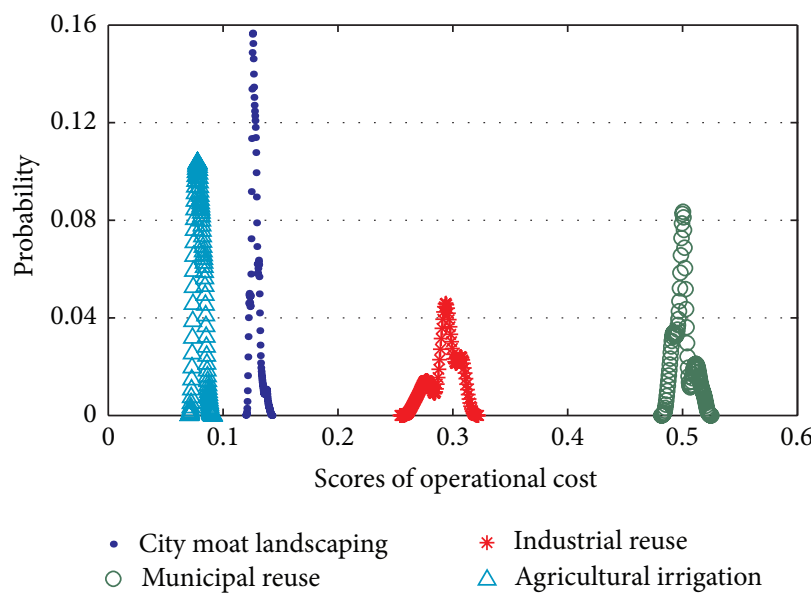

(c)

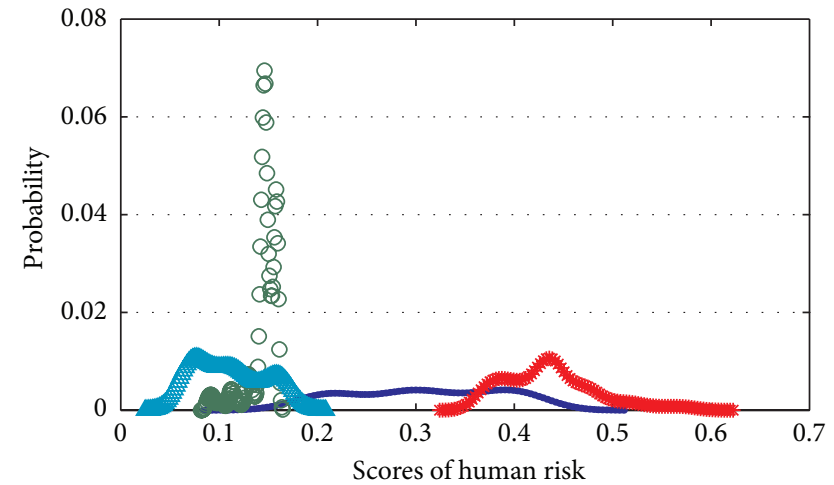

(b)

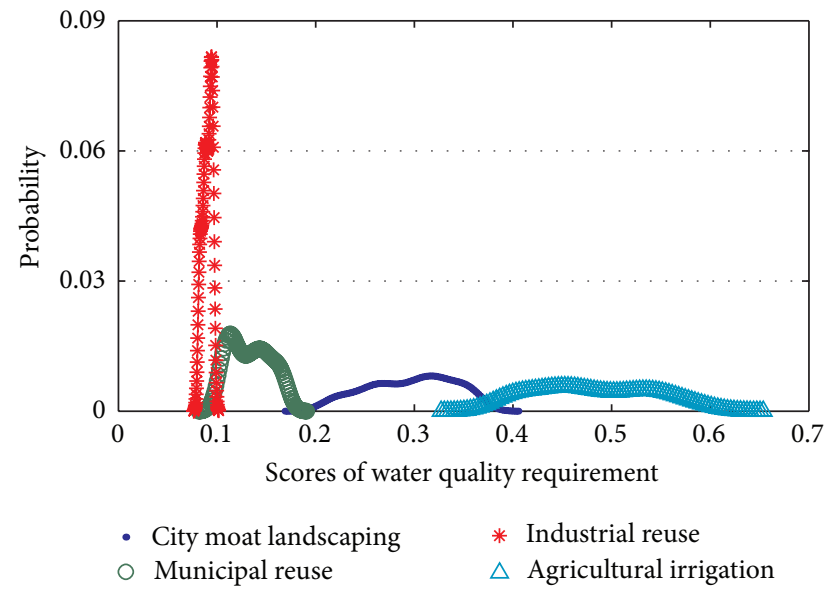

(d)

Figure 2: Probability density estimates of alternative scores with regard to the subcriterion of (a) applicability, (b) human risk, (c) operational cost, and (d) water quality requirement.

and flushing toilets in public buildings and households. It should be noted that effluent from the WWTP usually needs to be further disinfected to such an extent that is safe from a microbiological point of view. Reclaimed water may also serve industrial processes (e.g., cooling, boiler feed, and process water) after proper treatment to prevent scaling, corrosion, bacterial fouling, and foaming issues. However, its feasibility and economic applicability vary from case to case. For example, the electroplating process requires water of high quality to wash circuit boards while tanneries can use low-quality water for washing hides. Lastly, agricultural irrigation using treated wastewater (reclaimed water) is becoming a common practice in arid and semiarid regions. Treated wastewater can be directly or indirectly (e.g., after disinfection) applied for irrigation depending on its quality and usage. As depicted in Figure 1, these four alternatives were evaluated based on technical, economic, and environmental criteria adopted from the literature and expert recommendations [7].

3.2.2. Data Acquisition. Both quantitative and qualitative data were collected through questionnaire survey and the literature review. Key numbers such as capital cost and operational cost were obtained from different sources as shown in Table 1 . They were normalized using a linear value function as follows:

$$
b_{k}= \pm \frac{x_{k}}{\sum_{k=1}^{m} x_{k}}
$$

where $b_{k}$ is the normalized performance score of the $k$ th alternative in terms of a criterion, $m$ is the number of alternatives, and $x_{k}$ is the numerical value of the $k$ th alternative. It should be noted that quantitative data has either increasing (e.g., benefit) or decreasing (e.g., cost, risk) behavior. Therefore, positive scores (between 0 and 1) were given to those with increasing values, while negative scores (between -1 and 0 ) were assigned to the decreasing values. Normalized values for different alternatives with respect to reclaimed wastewater reuse are reported in Table 2. In the absence of available quantitative data, expert subjective rankings were used to evaluate the alternatives in terms of other criteria. Five experts from local authorities (Bureau of Environmental Protection) and educational institutions (professors and graduate students at Memorial University of Newfoundland) were asked to assess the hierarchy with interval judgments. Equation (7) and Table 3 show an example of expert assessments in regard to human risk. The number of Monte Carlo iterations used in 


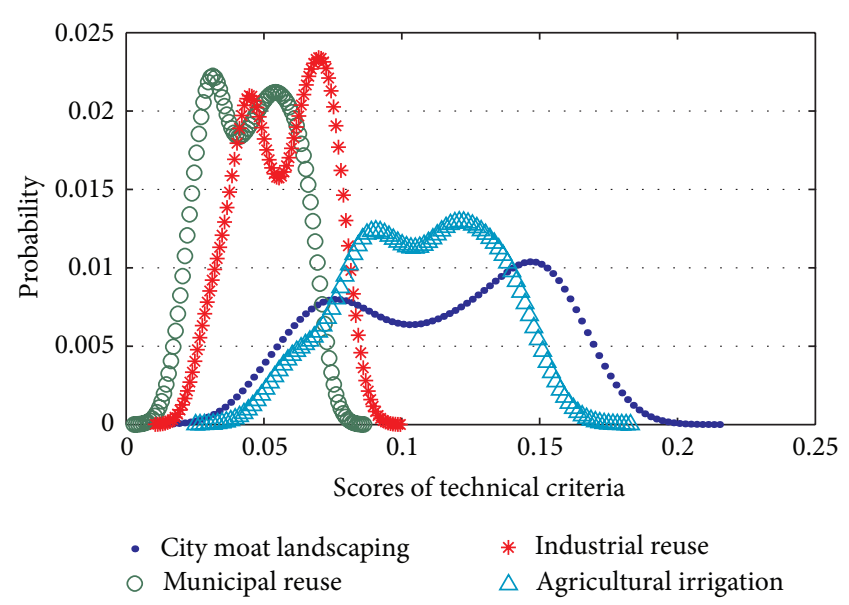

(a)

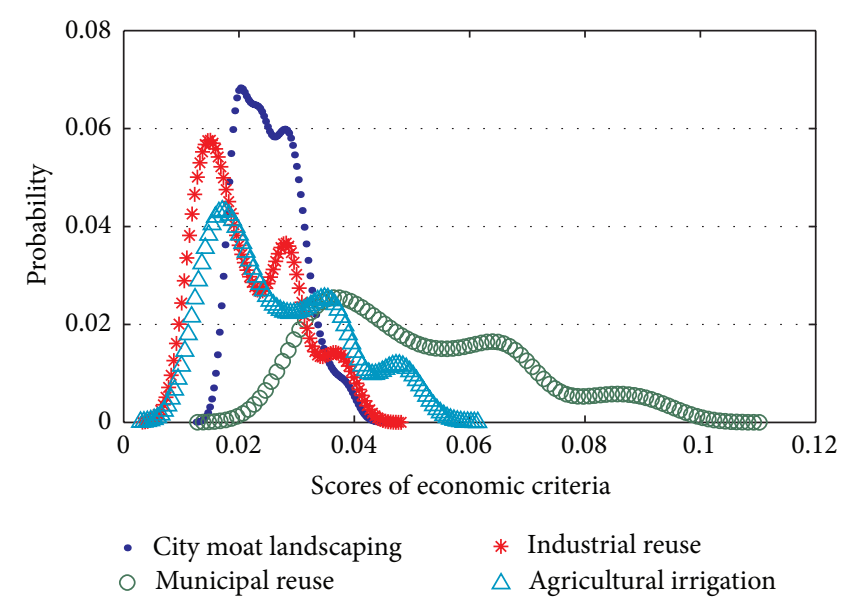

(b)

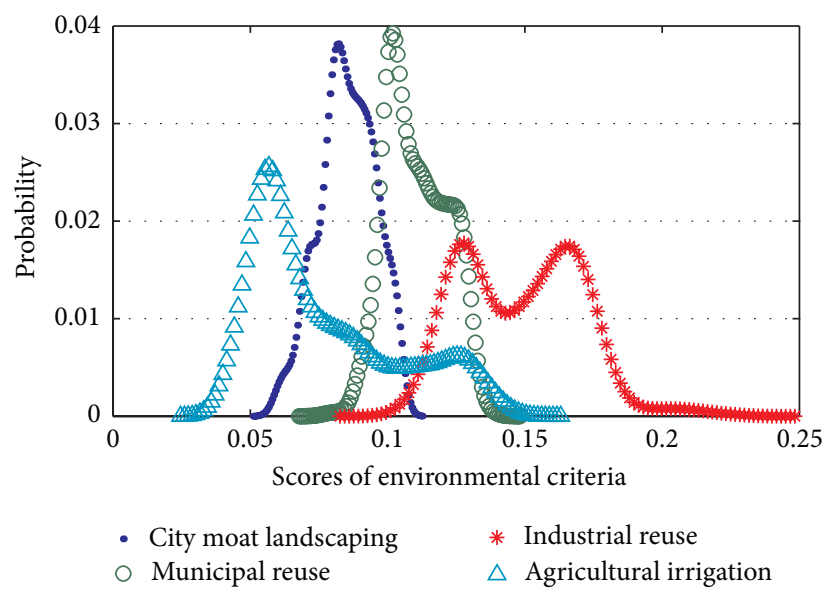

(c)

FIGURE 3: Probability density estimates of the overall alternative scores with regard to (a) technical criteria, (b) economic criteria, and (c) environmental criteria.

this case study was set as 1000 by considering time constraints and convergence speed.

$$
\begin{aligned}
& \begin{array}{llll}
C M L & M R & I R & A I
\end{array}
\end{aligned}
$$

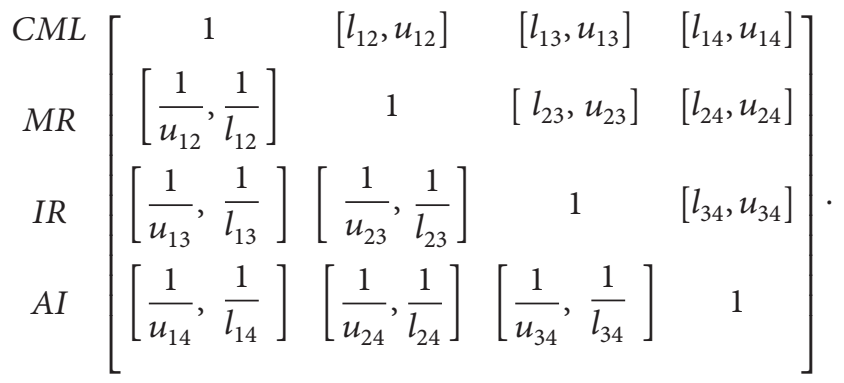

\section{Results and Discussion}

As shown in Figure 2, the alternative priorities with respect to some subcriteria are depicted in the form of probability density estimates using the kernel-smoothing method. It clearly shows that most density estimates have two major peaks, indicating that the optimization results obtained from the LGP method tend to be concentrated within a certain interval possibly due to the randomly generated interval judgments. A few density estimates appear to be smooth and continuous over a large span while many others are steep and bell shaped. This may be attributable to expert assessments which diverge on unfamiliar knowledge (e.g., the application of city moat landscaping) but converge on some commonly agreed upon principles.

The overall alternative priorities with regard to the whole sets of technical, economic, and environmental criteria are synthesized in Figure 3. City moat landscaping and agricultural irrigation have the best technical performance in most replications mainly due to their ease of operation and maintenance. Their overlaps with other alternatives are not statistically significant (Figure 3(a)); however, their own overlap reveals itself with a strong correlation coefficient of (0.956). Municipal reuse is seemingly preferred over the other options in terms of economic concerns (Figure 3(b)). This is more or less in agreement with the reality that reusing 


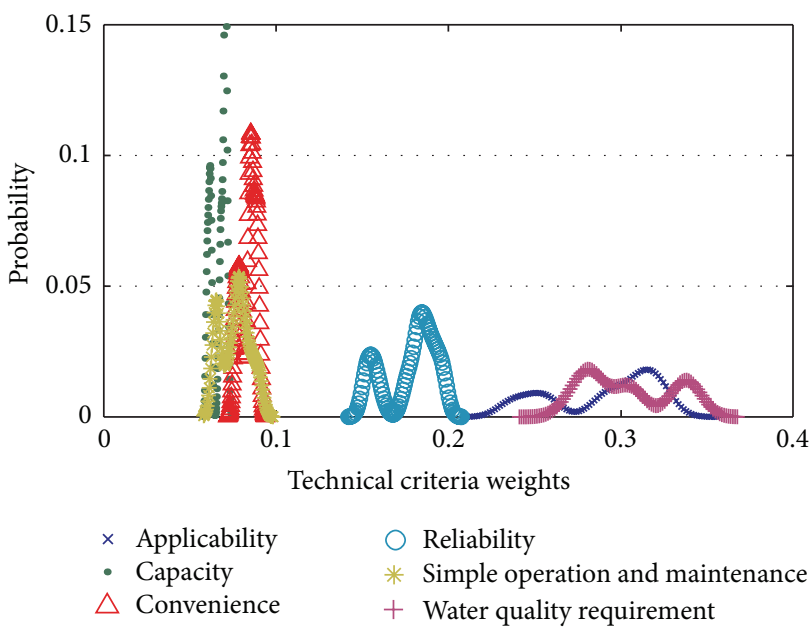

(a)

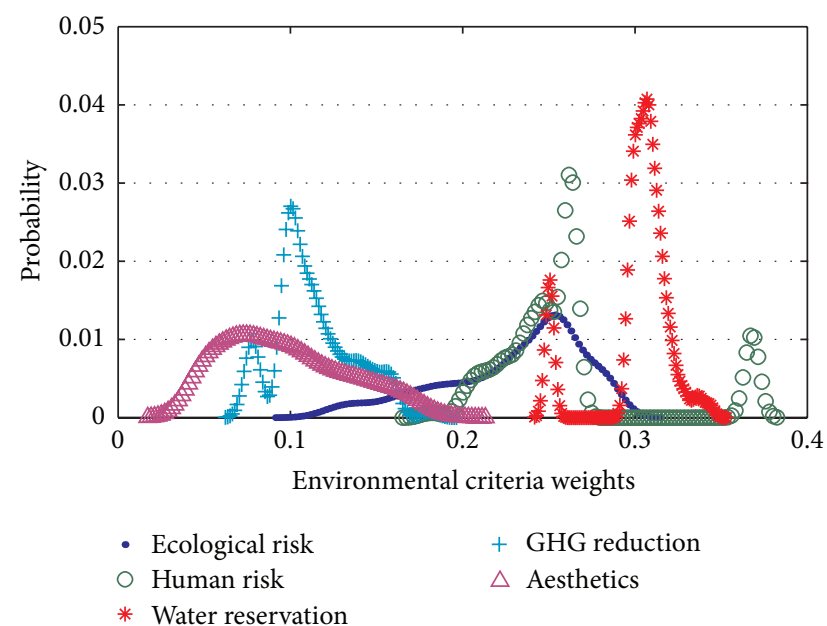

(c)

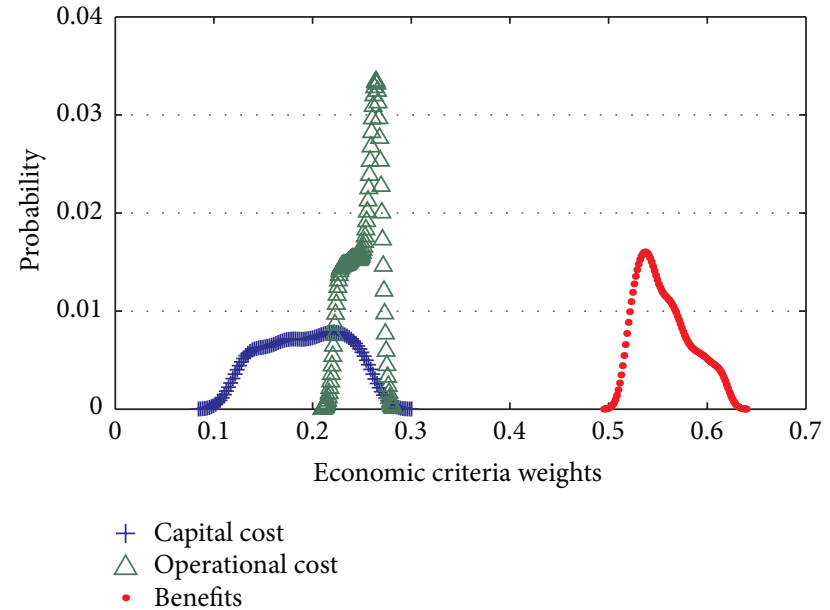

(b)

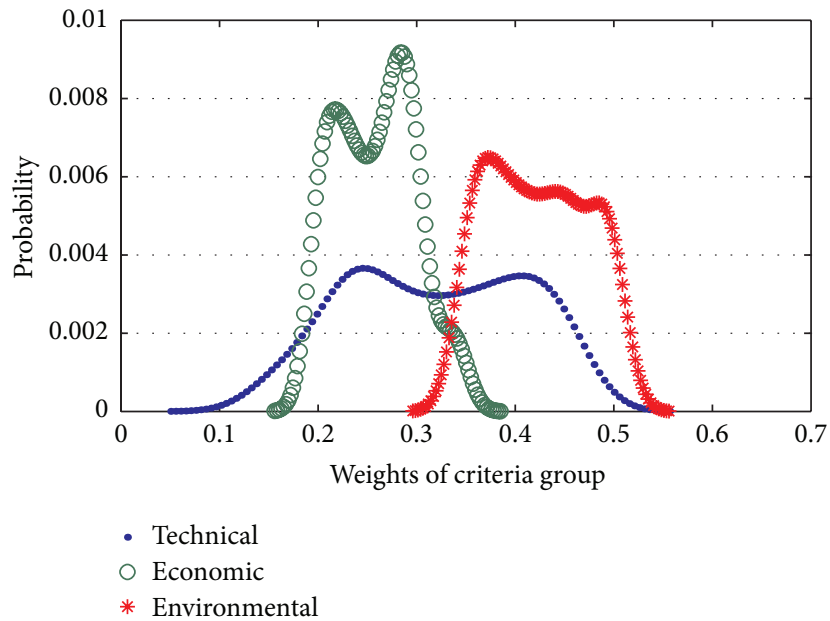

(d)

Figure 4: Probability density estimates of the relative weights between each (a) technical subcriterion, (b) economic sub-criterion, (c) environmental subcriterion, and (d) criteria group.

reclaimed water for municipal purposes can save extra costs of posttreatment and therefore creates more economic benefits. The correlation coefficients between the alternatives are all above 0.950 which suggests that their performance is positively correlated such that the increase of one is associated with the increase of the others. This can be further interpreted that the alternatives are not well distinguishable in terms of economic considerations; therefore, the significance of economic criteria is attenuated as demonstrated in Figures 3 (b) and 4(d). From the perspective of environmental conservation, industrial reuse dominates the others in more than 95\% of the replications (Figure 3(c)). This seems to fit the way most people think because using treated wastewater in industrial sectors can hardly cause any environmental issues or raise human health concerns.

The probability density distributions of subcriterion weights are demonstrated in Figure 4 using the kernelsmoothing method. Applicability and water quality requirement are the most influential technical subcriteria, followed by reliability. Benefit absolutely dominates other two economic subcriteria with the confidence level of 100\%. Environmental subcriteria are to some extent tangle with each other while water reservation manages to lead in $89.2 \%$ of the replications. These aforementioned subcriteria should be prioritized and further considered in the decision making process if the final alternative scores are too close. The final scores of each decision alternative are plotted in Figure 5. It appears that industrial reuse $(0.18-0.3)$ is more preferred over municipal reuse $(0.16-0.25)$ or agricultural irrigation $(0.17-0.26)$ though the existence of overlaps may contradict this assertion. Further analysis indicates that industrial reuse takes the first or second places in over $88.6 \%$ of the replications while this number for the other two options is somewhere between $20 \%$ and $30 \%$ (Table 4 ). Another worthy mentioned finding is related to the final score of city moat landscaping which spans over a large range from 0.11 to 0.31 (Figure 5). This range is larger than those of other alternatives mainly because of the great divergence of expert opinions. 


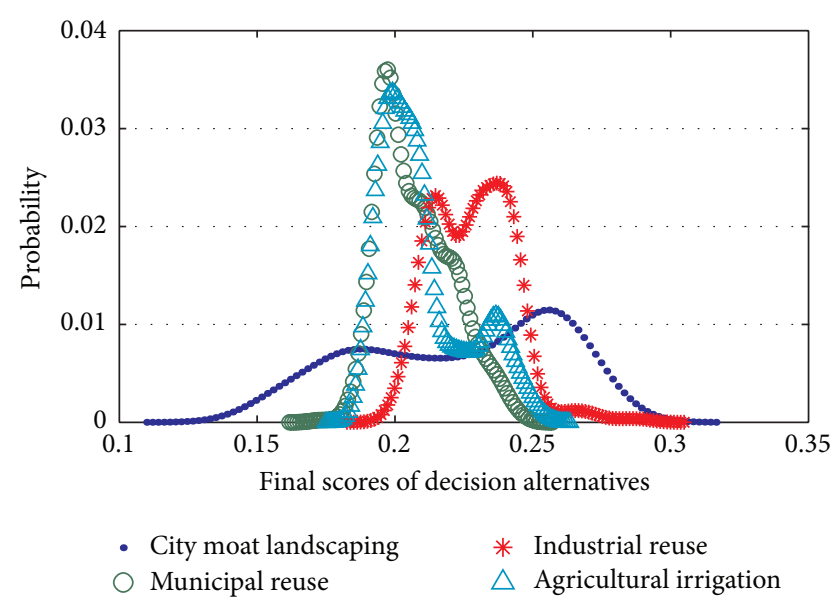

Figure 5: Probability density estimates of the final scores of decision alternatives.

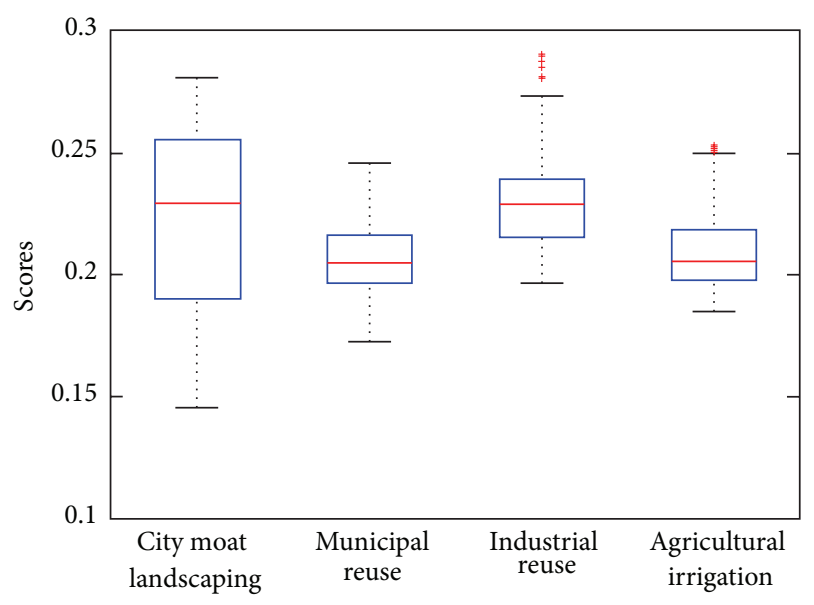

FIgURE 6: Box plots of overall scores of each alternative.

TABLE 4: Summary of the evaluation results of the SIAHP approach.

\begin{tabular}{lcccc}
\hline \multirow{2}{*}{ Decision alternative } & \multicolumn{4}{c}{ Rank } \\
& 1 & 2 & 3 & 4 \\
\hline City moat landscaping & 542 & 80 & 25 & 353 \\
Municipal reuse & 1 & 206 & 468 & 325 \\
Industrial reuse & 397 & 489 & 106 & 8 \\
Agricultural irrigation & 60 & 225 & 401 & 314 \\
\hline Total & 1000 & 1000 & 1000 & 1000 \\
\hline
\end{tabular}

In other words, some experts may favor city moat over the others (in $54.2 \%$ replications), whereas some experts may rank it as the least preferable solution (in 35.3\% replications) (Table 4). Figure 6 confirms these observations by using box plot to graphically illustrate the minimum, lower quartiles, medians, upper quartiles, and maximum of alternative overall scores. It can be argued that choosing industrial reuse seems to give the best overall account of technical, economic, and environmental concerns.
It is worth discussing the correlations between the final scores as this can help decision makers further interpret the experts' preferences. City moat landscaping and industrial reuse are in conflict with each other as their correlation coefficient is -0.858 , implying that experts tend not to choose both options as their favorite (Figure 7(a)). The correlation coefficients between industrial reuse and municipal reuse, industrial reuse and agricultural irrigation, and municipal and agricultural irrigation are $0.701,0.508$, and 0.835 , respectively, which agrees with the positive correlations shown in Figures 7(b)-7(d). That is to say, when either one of these three is favored by an expert, it is highly probable that the other two are also more or less favored.

\section{Conclusions}

This paper presents a hybrid stochastic-interval analytic hierarchy process (SIAHP) approach to address uncertainty issues in the decision making procedure by integrating interval judgments, probabilistic distributions, the lexicographic goal programming method, and Monte Carlo simulation. A case study of selecting the best effluent reuse strategy for a WWTP in the city of Shuangcheng, China, was carried out to verify the feasibility and efficiency of the proposed approach. Four candidate alternatives including city moat landscaping, municipal reuse, industrial reuse, and agricultural irrigation were evaluated by five experts from local authorities and educational institutions. Technical, economic, and environmental criteria and their associated sub-criteria were considered to investigate the performance of the alternatives. The results show that a few density estimates of alternative performance with regard to several subcriteria appear to be smooth and continuous over a large span while many others are steep and bell shaped. This may be attributable to expert assessments that diverge on unfamiliar knowledge but converge on some commonly agreed upon principles. City moat landscaping and agricultural irrigation have the best technical performance in most replications mainly due to their ease of operation and maintenance. Their own overlap is evident with a strong correlation coefficient of 0.956 . Municipal reuse is seemingly preferred over the other options in terms of economic concerns while the correlation coefficients between all alternatives are above 0.950 . This can be further interpreted that the alternatives are not well distinguishable in terms of economic considerations; therefore, the significance of economic criteria is attenuated. Industrial reuse seems to be the best option in terms of environmental reservation. Based on the final overall scores, industrial reuse $(0.18-0.3)$ is more preferred than municipal reuse $(0.16-0.25)$ or agricultural irrigation $(0.17-0.26)$ in most replications. The final score of city moat landscaping ranges from 0.11 to 0.31 which is larger than those of other alternatives mainly because of the great divergence of expert opinions. In other words, some experts may favor it over the others (in $54.2 \%$ replications), whereas some experts may rank it as the least preferable solution (in 35.3\% replications). It can be concluded that choosing industrial reuse seems to give the best overall account of technical, economic, and 


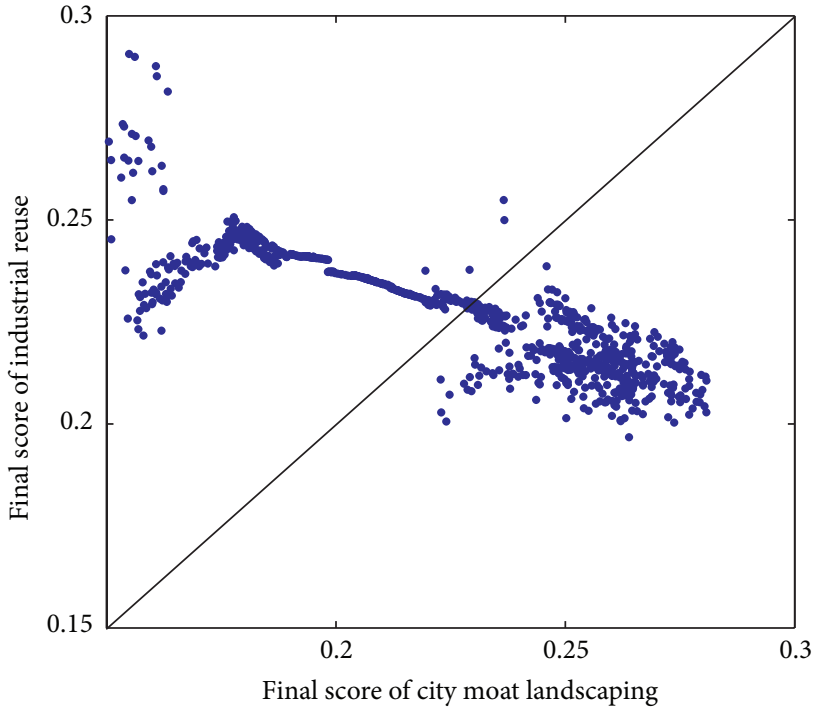

(a)

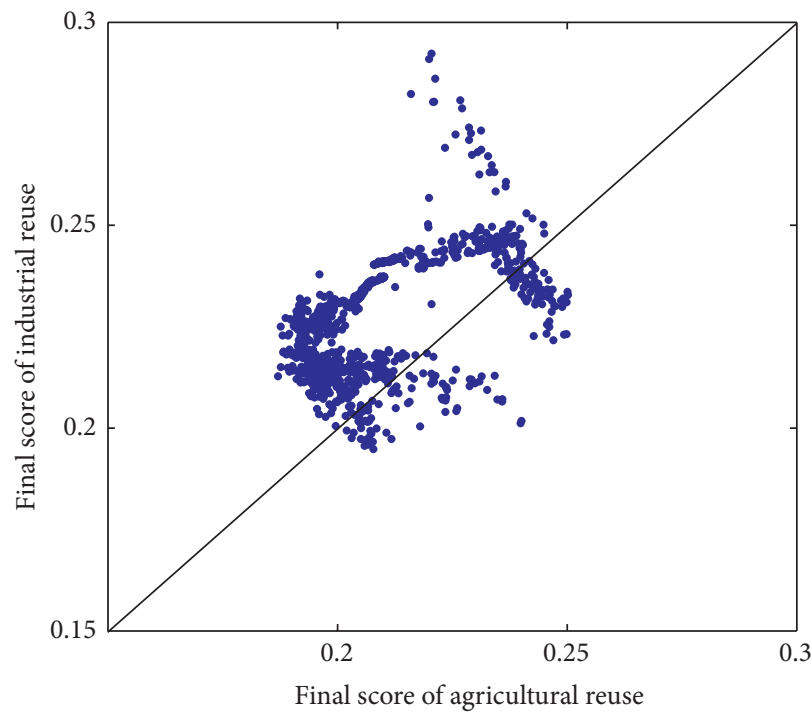

(c)

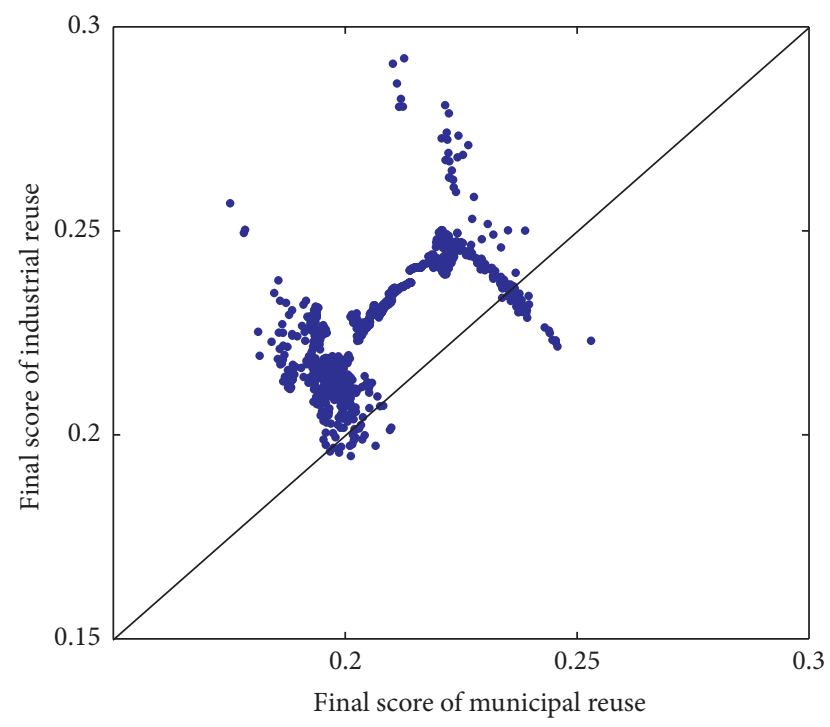

(b)

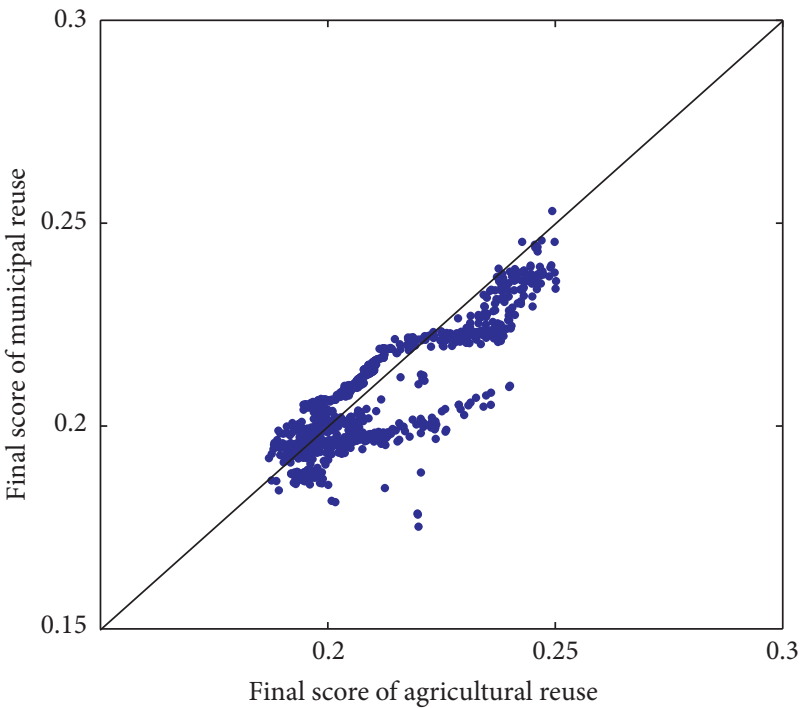

(d)

FiguRE 7: Scatter plots of the final scores of (a) city moat landscaping versus industrial reuse, (b) municipal reuse versus industrial reuse, (c) agricultural reuse versus industrial reuse, and $(\mathrm{d})$ agricultural reuse versus municipal reuse.

environmental concerns. The proposed SIAHP approach can aid group decision making by accommodating linguistic information and dealing with insufficient information or biased opinions.

\section{Acknowledgments}

The study was supported by the National Natural Science Foundation of China (nos. 51179070 and 51209089), the Natural Science and Engineering Research Council of Canada, and the United Nations Development Programme (UNDP) as well as the China International Center for Economic and Technical Exchanges (CICETE) of the Ministry of Commerce of China.

\section{References}

[1] G. O. Engin, B. S. Ucar, and E. Senturk, "Reuse feasibility of pre-treated grey water and domestic wastewater with a compact household reverse osmosis system," Desalination and Water Treatment, vol. 29, no. 1-3, pp. 103-109, 2011.

[2] L. Jing and B. Chen, "Hydrological monitoring and modelling of the Deer River Watershed with SLURP," Journal of Environmental Informatics, vol. 17, no. 1, pp. 36-45, 2011.

[3] B. Chen, L. Jing, B. Y. Zhang, and S. Liu, "Wetland monitoring, characterization and modeling under changing climate in the Canadian subarctic," Journal of Environmental Informatics, vol. 18, no. 2, pp. 55-64, 2011.

[4] Y. R. Fan and G. H. Huang, "A robust two-step method for solving interval linear programming problems within an 
environmental management context," Journal of Environmental Informatics, vol. 19, no. 1, pp. 1-9, 2012.

[5] S. Agidi, S. Vedachalam, K. Mancl, and J. Lee, "Effectiveness of onsite wastewater reuse system in reducing bacterial contaminants measured with human-specific IMS/ATP and qPCR," Journal of Environmental Management, vol. 115, pp. 167-174, 2013.

[6] E. Friedler, O. Lahav, H. Jizhaki, and T. Lahav, "Study of urban population attitudes towards various wastewater reuse options: Israel as a case study," Journal of Environmental Management, vol. 81, no. 4, pp. 360-370, 2006.

[7] S. J. You and D. C. Wu, "Potential for reuse of high cellulose containing wastewater after membrane bioreactor treatment," Desalination, vol. 249, no. 2, pp. 721-728, 2009.

[8] H. Kon and M. Watanabe, "Construction of a treated wastewater reuse system for renewal of a water cycle mechanism in urban areas-modeling analysis of reclamation treatment processes corresponding to target water quality by use," Desalination and Water Treatment, vol. 6, no. 1-3, pp. 5-11, 2009.

[9] L. Jing, B. Chen, B. Y. Zhang, P. Li, and J. S. Zheng, "Monte Carlo simulation-aided analytic hierarchy process approach: case study of assessing preferred non-point source pollution control best management practices," ASCE Journal of Environmental Engineering, 2013.

[10] J. R. Yu, Y. W. Hsiao, and H. J. Sheu, "A multiplicative approach to derive weights in the interval analytic hierarchy process," International Journal of Fuzzy Systems, vol. 13, no. 3, pp. 225231, 2011.

[11] B. Chen, G. H. Huang, and Y. F. Li, "Pesticide-loss simulation and risk assessment during flooding season-a study in the Auglaize-Blanchard Watershed," Water Internationalno, vol. 30, no. 1, pp. 88-98, 2005.

[12] B. Chen, H. C. Guo, G. H. Huang et al., "ASRWM: an arid/semiarid region water management model," Engineering Optimization, vol. 37, no. 6, pp. 609-631, 2005.

[13] L. Jing, B. Chen, B. Y. Zhang, and H. X. Peng, "A review of ballast water management practices and challenges in harsh and arctic environments," Environmental Reviews, vol. 20, pp. 83108, 2012.

[14] P. Li and B. Chen, "FSILP: fuzzy-stochastic-interval linear programming for supporting municipal solid waste management," Journal of Environmental Management, vol. 92, pp. 1198-1209, 2011.

[15] T. L. Saaty, The Analytic Hierarchy Process: Planning, Priority Setting and Resource Allocation, McGraw-Hill, New York, NY, USA, 1980.

[16] M. P. Amiri, "Project selection for oil-fields development by using the AHP and fuzzy TOPSIS methods," Expert Systems With Applications, vol. 37, no. 9, pp. 6218-6224, 2010.

[17] S. Chowdhury and T. Husain, "Evaluation of drinking water treatment technology: an entropy-based fuzzy application," Journal of Environmental Engineering ASCE, vol. 132, no. 10, pp. 1264-1271, 2006.

[18] T. Kaya and C. Kahraman, "An integrated fuzzy AHP-ELECTRE methodology for environmental impact assessment," Expert Systems With Applications, vol. 38, pp. 8553-8562, 2011.

[19] R. Sadiq and S. Tesfamariam, "Environmental decision-making under uncertainty using intuitionistic fuzzy analytic hierarchy process (IF-AHP)," Stochastic Environmental Research and Risk Assessment (SERRA), vol. 23, no. 1, pp. 75-91, 2009.
[20] E. Tolga, M. L. Demircan, and C. Kahraman, "Operating system selection using fuzzy replacement analysis and analytic hierarchy process," International Journal of Production Economics, vol. 97, no. 1, pp. 89-117, 2005.

[21] E. S. Rosenbloom, "A probabilistic interpretation of the final rankings in AHP," European Journal of Operational Research, vol. 96, no. 2, pp. 371-378, 1997.

[22] R. Banuelas and J. Antony, "Modified analytic hierarchy process to incorporate uncertainty and managerial aspects," International Journal of Production Research, vol. 42, no. 18, pp. 38513872, 2004.

[23] D. Carlucci and G. Schiuma, "Applying the analytic network process to disclose knowledge assets value creation dynamics," Expert Systems with Applications, vol. 36, no. 4, pp. 7687-7694, 2009.

[24] T. C. Wang and Y. H. Chen, "Applying consistent fuzzy preference relations to partnership selection," Omega, vol. 35, pp. 384388, 2007.

[25] A. Andronikidis, A. C. Georgiou, K. Gotzamani, and K. Kamvysi, "The application of quality function deployment in service quality management," TQM Journal, vol. 21, no. 4, pp. 319-333, 2009.

[26] Y.-M. Wang, J.-B. Yang, and D.-L. Xu, "A two-stage logarithmic goal programming method for generating weights from interval comparison matrices," Fuzzy Sets and Systems, vol. 152, no. 3, pp. 475-498, 2005.

[27] B. Chandran, B. Golden, and E. Wasil, "Linear programming models for estimating weights in the analytic hierarchy process," Computers and Operations Research, vol. 32, no. 9, pp. 22352254, 2005.

[28] T. Rezaei Taziani, M. Sanei, G. R. Jahanshahloo, J. Jablonsky, and M. R. Mozaffari, "Ranking bank branches with interval data by IAHP," International Journal of Mathematical Analysis, vol. 3, no. 17-20, pp. 971-983, 2009.

[29] T.-H. Hsu and F. F. C. Pan, "Application of Monte Carlo AHP in ranking dental quality attibutes," Expert System With Applications, vol. 36, pp. 2310-2316, 2009.

[30] U.S. EPA, "Guidelines For Water Reuse, Municipal Support Division, Office of Wastewater Management, Office of Water, Washington, DC, USA, 2004.

[31] H. Yang and K. C. Abbaspour, "Analysis of wastewater reuse potential in Beijing," Desalination, vol. 212, no. 1-3, pp. 238-250, 2007. 


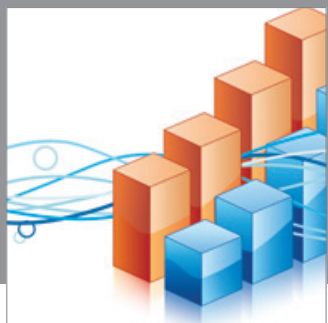

Advances in

Operations Research

mansans

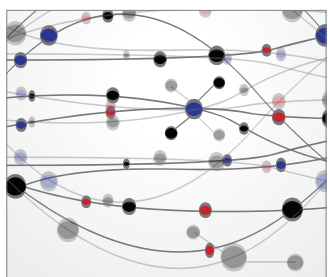

The Scientific World Journal
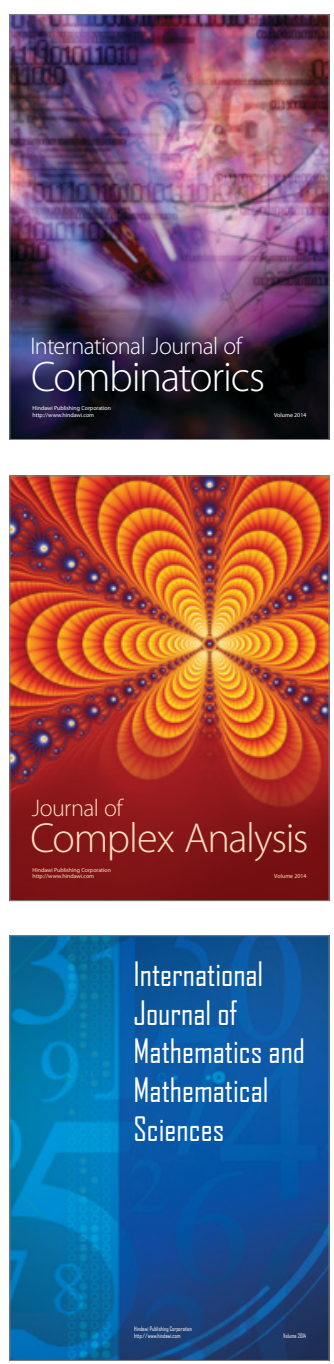
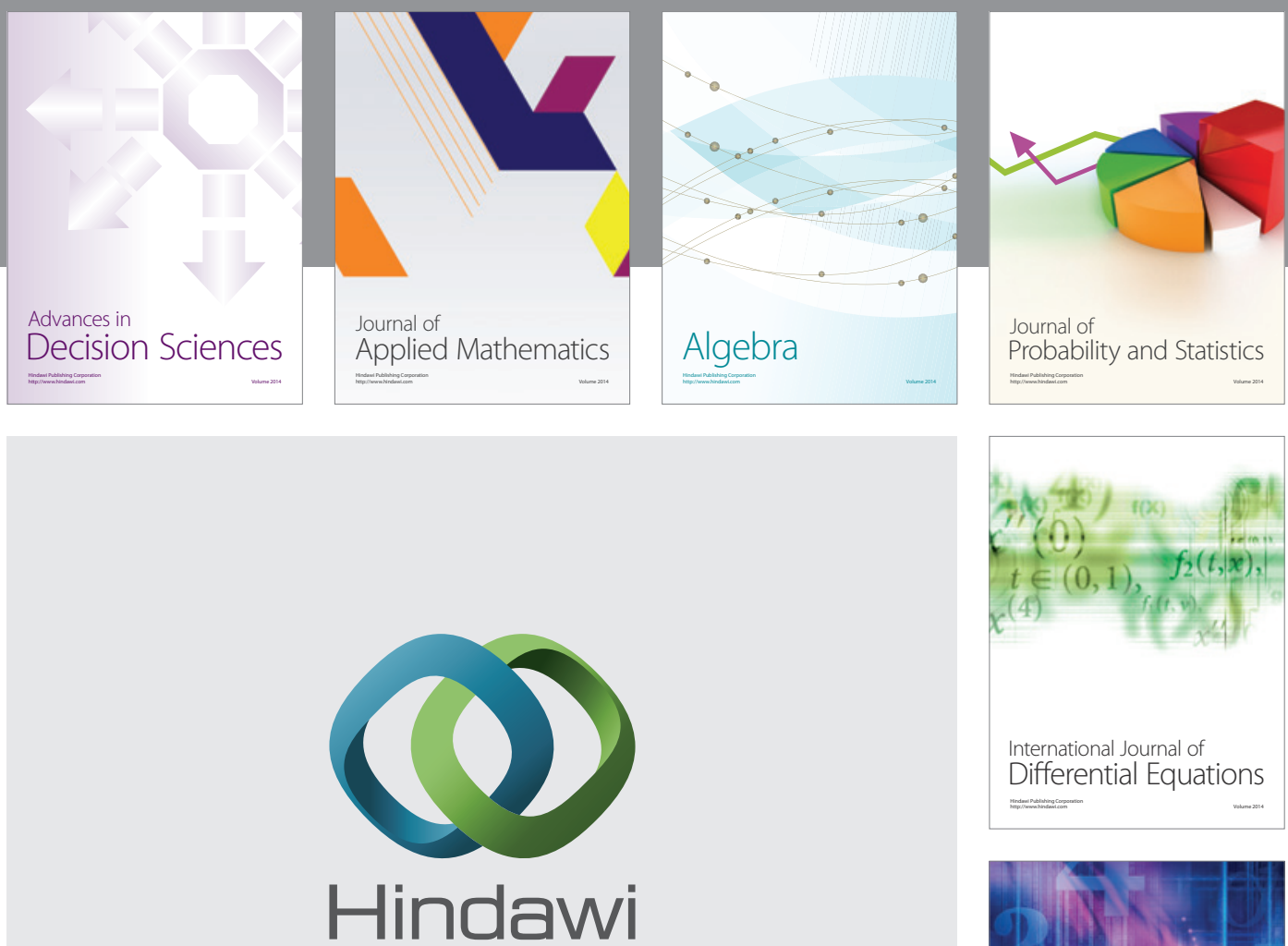

Submit your manuscripts at http://www.hindawi.com
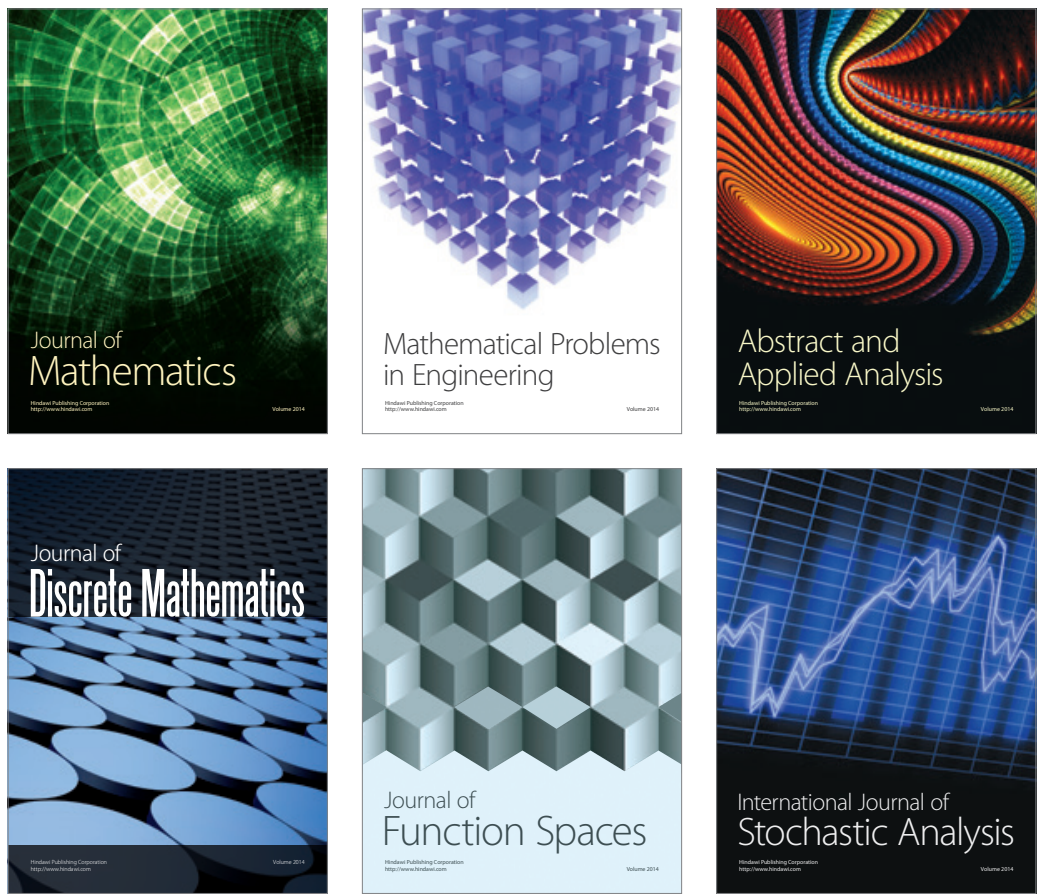

Journal of

Function Spaces

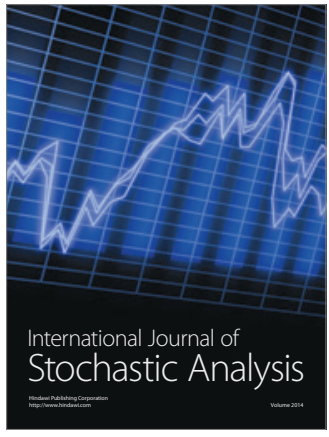

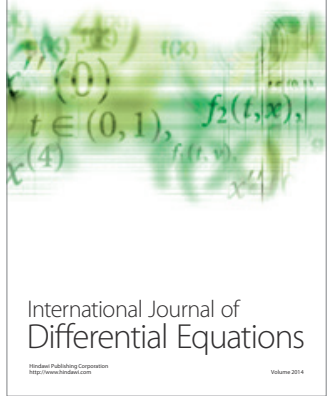
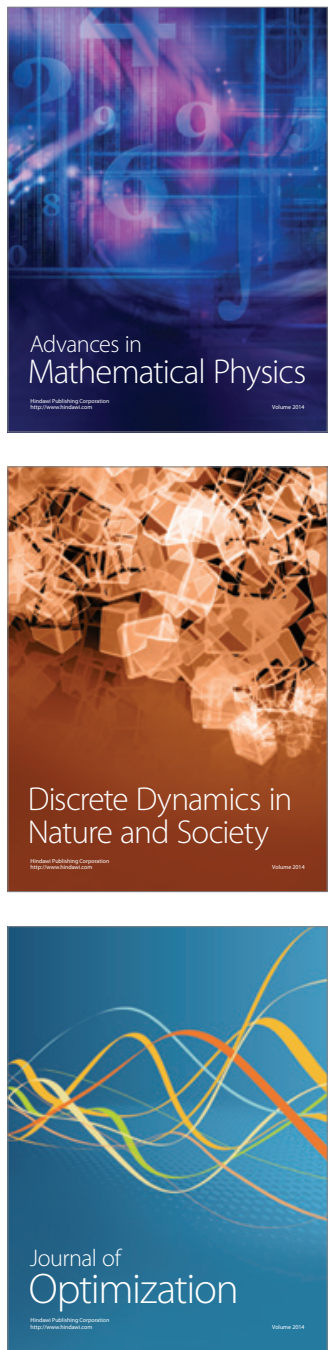